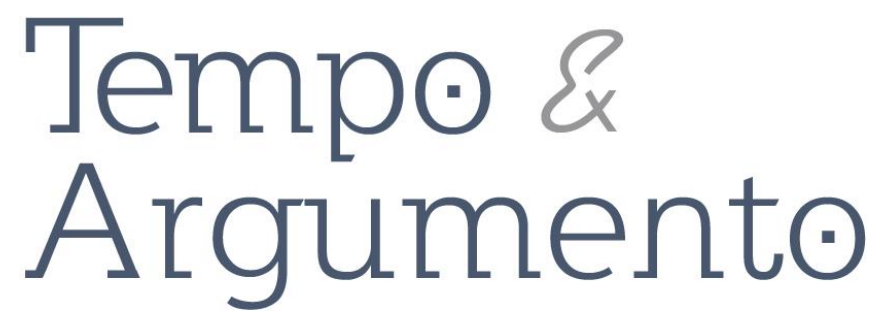

\title{
Cinematógrafos de guerra: cinema e propaganda estadunidense no Brasil durante a II Guerra Mundial
}

\section{Resenha da obra:}

VALIM, Alexandre Busko. O Triunfo da persuasão: Brasil, Estados Unidos e a Política da BoaVizinhança durante a II Guerra Mundial. São Paulo: Ed. Alameda, 2017.

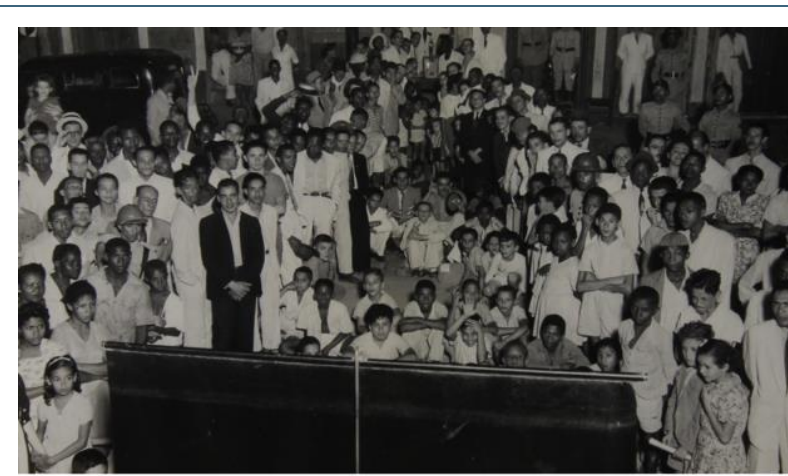

\section{O Triunfo da Persuasão}

Brasil, Estados Unidos e o Cinema da Política de Boa Vizinhança durante a II Guerra Mundial

Alexandre Busko Valim

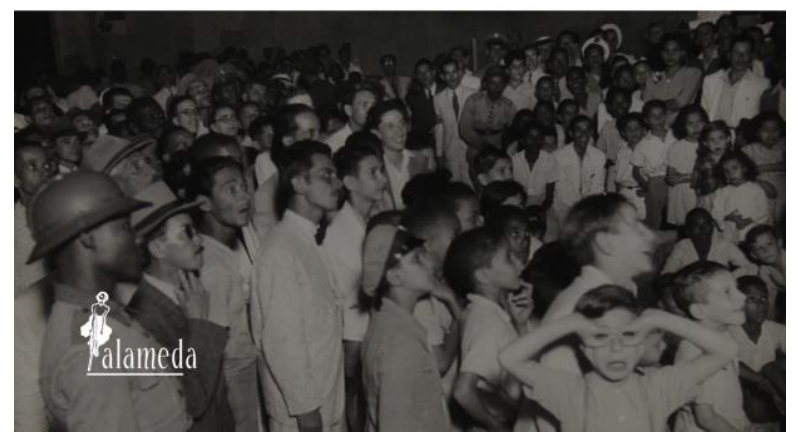

\section{Autora da resenha}

Ana Marília Carneiro

Doutora em História pela Universidade Federal de Minas Gerais (UFMG). Belo Horizonte, MG - BRASIL anammc@gmail.com orcid.org/0000-0002-3665-8942

\section{Para citar esta resenha:}

VALIM, Alexandre Busko. O Triunfo da persuasão: Brasil, Estados Unidos e a Política da Boa-Vizinhança durante a II Guerra Mundial. São Paulo: Ed. Alameda, 2017. Resenha de: CARNEIRO, Ana Marília. Cinematógrafos de guerra: cinema e propaganda estadunidense no Brasil durante a II Guerra Mundial. Revista Tempo e Argumento, Florianópolis, v. 11, n. 26, p. 635 - 640. jan./abr. 2019. 
A obra que temos em mãos trata de um tema caro às experiências bélicas do século XX: a propaganda como arma de guerra e instrumento de persuasão na formação de consenso em torno da hegemonia estadunidense na América Latina. Em contraste com a barbárie e a violência emergentes dos confrontos da II Guerra Mundial, a máquina de guerra mobilizada para conquistar mentes, corações e aliados em meio ao campo de batalha consistiu em uma das expressões mais extraordinárias e fascinantes da cultura contemporânea: o cinema.

O livro de Alexandre Busko Valim, O Triunfo da persuasão. Brasil, Estados Unidos e a Política da Boa-Vizinhança durante a II Guerra Mundial, publicado em 2017, dedica-se ao estudo da dinâmica da produção e difusão da propaganda estadunidense por meio do cinema no Brasil, alvo estratégico e privilegiado da campanha dos aliados em meio ao turbulento cenário da II Guerra Mundial. Resultado de uma pesquisa de fôlego, a obra é amparada no valioso e robusto acervo de fontes documentais referentes ao Office of the Coordinator of Inter-American Affairs - Office, consultadas no National Archives dos Estados Unidos. Ainda pouco exploradas pela literatura dedicada às relações interamericanas, as fontes - e, sem dúvida, a habilidade do autor aliada a um fecundo diálogo com a bibliografia especializada - permitiram a construção de uma narrativa potente, permeada de relatos surpreendentes e informações impactantes.

Um dos importantes diferenciais do estudo de Alexandre Valim é sua perspectiva de análise: o autor se esquiva de uma abordagem mais tradicional fundamentada na análise fílmica e pensa o cinema - e a problemática histórica - munido de uma visão mais ampla, como um fenômeno que envolve diversas dimensões. Ou seja, o cinema, como objeto de estudo, deve ser compreendido como um conjunto de práticas sociais que escapa à simples análise das fontes visuais, conduzindo o pesquisador em direção a um tratamento mais abrangente da visualidade como uma dimensão importante da vida social e dos processos sociais (MENESES, 2003, p. 11).

Para além da compreensão do cinema como mero entretenimento e obra estética, um estudo mais denso do âmbito cinematográfico exige que o investigador esteja atento à capacidade de influência, persuasão e encantamento do público através do cinema, ao uso de filmes como veículos de difusão de determinadas políticas, valores e culturas, à 
análise das suas condições de produção, exibição e distribuição, além da complexa rede de sociabilidades e relações de poder envolvidas na sua realização. Todas essas questões estão presentes no texto de Alexandre Valim, que situa a análise da propaganda estadunidense por meio do cinema atrelada a uma contraofensiva de guerra na qual estava em jogo, para os Estados Unidos, a conquista de parceiros econômicos e aliados políticos na América Latina.

Criado em 1940, por determinação do presidente Franklin Roosevelt, para coordenar as relações comerciais e culturais entre os Estados Unidos e os países latinoamericanos, o Office representou, de maneira emblemática, o notável esforço de mobilização da nascente indústria cultural em favor da manutenção da posição hegemônica dos Estados Unidos na América Latina durante a II Guerra Mundial. Dentre os múltiplos âmbitos de atuação do Office, Valim se debruça sobre as atividades de propaganda difundidas através do cinema, um empreendimento posto em marcha pela Divisão de Cinema do Office e pela primeira unidade do Office na América Latina, a Brazilian Division.

Os atores envolvidos nessa trama não pertencem somente ao quadro de funcionários da agência governamental estadunidense; ao longo das páginas, nos deparamos com sujeitos de alta performance como Walt Disney, Nelson Rockefeller, Carmen Miranda, Orson Welles, empresários dos grandes estúdios de cinema de Hollywood, embaixadores dos Estados Unidos e agentes do Departamento de Imprensa e Propaganda do presidente Getúlio Vargas. No entanto, é fundamental recordar: a propaganda possui um alvo privilegiado; nesse caso específico, a plateia. Essa é a audiência que deve ser persuadida.

Um dos plot points da obra é justamente o capítulo intitulado O Show Precisa Continuar: o cinema da boa vizinhança adentra o país. Nesta parte do texto são retratadas as diversas dificuldades e obstáculos enfrentados pelas equipes da Brazilian Division para realizar exibições de filmes nas pequenas cidades do interior do país. As incursões consistiam em verdadeiras sagas, e envolviam o deslocamento dos projetistas e seus pesados equipamentos através de estradas precárias, muitas vezes empregando o transporte de tração animal ou mesmo em lombos de mula, além de pequenos barcos e 
canoas. Às dificuldades de transporte em um país com as dimensões territoriais do Brasil somavam-se a falta de energia elétrica em muitas localidades, a inutilização dos filmes e projetores devido aos danos causados durante o transporte, às elevadas temperaturas ou à alta umidade, à impossibilidade de reposição de peças eventualmente danificadas durante as exibições, como lâmpadas, cabos, válvulas, transformadores. Todas essas adversidades de logística e transporte enfrentadas pela equipe da Brazilian Division nos ajudam a vislumbrar a dimensão da importância do projeto de disseminação em larga escala da propaganda estadunidense por meio do cinema.

A linguagem visual explorada neste capítulo é evocada de maneira recorrente: a partir de um dos projetos mais ousados experimentados no Brasil, as sessões de cinema realizadas em vagões de trens ou mesmo através dos Unit Mobiles, uma parceria com empresas do ramo farmacêutico que proporcionava automóveis adaptados com telas para exibir filmes, cinejornais e desenhos animados selecionados pela Brazilian Division e, ao mesmo tempo, comercializava, para o público, medicamentos como Leite de Magnésia, Melhoral e Pílulas de Vida do Dr. Ross. As impressionantes imagens fotográficas que acompanham o livro eternizaram as sessões de cinema a céu aberto realizadas em praças públicas de cidades do interior, penitenciárias, escolas, quartéis e até mesmo hospitais psiquiátricos. As exibições - sempre gratuitas - atingiam um amplo público espectador, proveniente não apenas da elite e da classe média, mas também das classes populares, composta muitas vezes por indivíduos que nunca haviam experimentado uma sessão de cinema e que permaneciam encantados por verem pela primeira vez um bombardeio de imagens em movimento.

E se o alvorecer do século XX foi iluminado por uma nova forma de linguagem visual, imagens em movimento difundidas pelos cinematográfos em escala mundial, é necessário refletir sobre o poder desse novo suporte e artefato cultural de gerar imaginários sociais e práticas representacionais. A pesquisa de Alexandre Valim não se debruça diretamente sobre o campo de recepção das películas estadunidenses entre o público brasileiro, entretanto, revela importantes aspectos: o primeiro, a existência de um pesado investimento em propaganda e na produção cinematográfica por parte do governo dos EUA; a grande capilaridade atingida no interior do Brasil através do projeto 
de popularização das exibições e a larga audiência alcançada, em grande medida formada por um público analfabeto. Certamente, não se deve tomar a esfera de influência do público, provocada pelos filmes de propaganda, de maneira mecânica e em via de mão única, afinal, a consciência não é uma tela em branco, e o campo da cultura é um campo de batalha, permeado por lutas e resistências. No entanto, como afirma Stuart Hall (2003, p. 240), as operações culturais estão ligadas aos mecanismos de hegemonia cultural em jogo, e há sempre posições estratégicas a serem conquistadas ou perdidas. E, como adverte Alexandre Valim (2017, p. 313), embora uma avaliação precisa sobre o cinema de propaganda no Brasil seja uma tarefa extremamente difícil de ser realizada, “o imenso volume de fontes produzidas pelas agências governamentais estadunidenses atuando em território brasileiro sugerem fortemente que esse impacto foi profundo e duradouro".

Vale ressaltar: o cinema "não é somente um conjunto de imagens, mas uma relação social entre pessoas, mediatizada por imagens"1. O sucesso de público nas exibições e o grande alcance do projeto propagandístico era fruto de um intenso esforço por parte do pessoal da Brazilian Division, que envolvia a mobilização de uma complexa rede de contatos, negociações e acordos entre autoridades locais, políticos, militares, funcionários do DIP e mesmo entre a alta cúpula do Office, uma vez que "o intenso contato com a realidade brasileira por estadunidenses que estiveram no país fez com que, frequentemente, estes flexibilizassem diretrizes elaboradas em Washington em prol de perspectivas mais humanistas e solidárias" (VALIM, 2017, p. 312).

Se, por um lado, o autor destaca a importância de compreender a diversidade dessas relações, representações e práticas estabelecidas entre os segmentos estadunidenses e latino-americanos, por vezes contraditórias e divergentes, por outro, não hesita em ratificar o imperialismo midiático presente no programa de propaganda estadunidense para a América Latina que perpassa os vários circuitos de relações de poder, reproduzindo e atualizando antigos métodos de controle e dominação.

\footnotetext{
1 A associação cinema-espetáculo foi apropriada de Guy Debord, para quem o espetáculo "não é um conjunto de imagens, mas uma relação social entre pessoas, mediatizada por imagens”. Cf. DEBORD, Guy. A Sociedade do Espetáculo. São Paulo: Contraponto, 1997, p. 12.
} 
O uso do cinema como recurso de aproximação entre os Estados Unidos e o Brasil durante a II Guerra Mundial teve um impacto sem precedentes, e não serviu apenas como instrumento de convencimento e persuasão no campo político-ideológico ou no controle de um estratégico mercado fornecedor de matérias-primas. O American Way of Life difundido através da propaganda no cinema vendia também novos hábitos, estilos, modas, costumes e comportamentos que transformaram de maneira decisiva a sociedade brasileira. Através de uma linguagem simples, o livro de Alexandre Valim traz uma análise sofisticada envolvendo propaganda, cinema e guerra, uma tríade de elementos importantes para a compreensão do poder de persuasão que serve de munição à indústria cinematográfica até os dias de hoje.

\section{Referências:}

DEBORD, Guy. A Sociedade do Espetáculo. São Paulo: Contraponto, 1997.

HALL, Stuart. Da diáspora: identidades e mediações culturais. Belo Horizonte: Editora da UFMG, 2003.

MENESES, Ulpiano T. Bezerra de. Fontes visuais, cultura visual, história visual. Balanço provisório, propostas cautelares. In: Revista Brasileira de História. São Paulo, v. 23, n. 45, 2003.

VALIM, Alexandre Busko. O Triunfo da persuasão: Brasil, Estados Unidos e a Política da Boa-Vizinhança durante a II Guerra Mundial. São Paulo: Ed. Alameda, 2017. 